Supporting Information

\title{
Magnetothermally Activated Nanometer-level Modular Functional Group Grafting of Nanoparticles
}

\author{
Yongjun Lim ${ }^{1,3}$, Seung-hyun Noh ${ }^{1}$, Tae-Hyun Shin ${ }^{1}$, Jung-uk Lee ${ }^{1,3}$, Dominik Lungerich, ${ }^{1,2}$ Jae-Hyun Lee ${ }^{1,2}$ and \\ Jinwoo Cheon ${ }^{*}, 1,2,3$ \\ ${ }^{1}$ Center for NanoMedicine, Institute for Basic Science (IBS), Seoul 03722, Republic of Korea. \\ ${ }^{2}$ Graduate Program of Nano Biomedical Engineering (NanoBME), Advanced Science Institute, Yonsei \\ University, Seoul 03722, Republic of Korea. \\ ${ }^{3}$ Department of Chemistry, Yonsei University, Seoul 03722, Republic of Korea.
}




\section{Characterization of magnetic nanoparticle (MNP) and PVP-coated MNP (MNP@PVP)}

a. Chemicals. All chemicals were purchased from Sigma-Aldrich. Iron (III) acetylacetonate (97\%), cobalt (II) chloride (anhydrous, 97\%), manganese (II) chloride (anhydrous, 97\%), hexane (95\%), oleylamine (70\%), oleic acid $(90 \%)$, octyl ether $(99 \%)$, and trioctylamine $(98 \%)$ were used to synthesize MNP without further purification. Azobisisobutyronitrile solution (AIBN, $0.2 \mathrm{M}$ in toluene) and $N$-vinylpyrrolidone (contains sodium hydroxide as inhibitor, $\geq 99 \%$ ) were used to introduce the PVP polymer shell.

b. Synthesis of the MNP. The core MNP, 15 nm CoFe $2 \mathrm{O}_{4} @ \mathrm{MnFe}_{2} \mathrm{O}_{4}$, were synthesized using the seed-mediated growth method reported in our previous work. ${ }^{1}$ Briefly, $9 \mathrm{~nm} \mathrm{CoFe} \mathrm{O}_{4}$ nanoparticles were first synthesized as follows. Iron (III) acetylacetonate $(5.00 \mathrm{mmol})$ and cobalt (II) chloride $(3.25 \mathrm{mmol})$ were mixed with oleylamine (91.17 mmol), oleic acid $(31.68 \mathrm{mmol})$, and octyl ether $(49.81 \mathrm{mmol})$ in a $250 \mathrm{~mL}$ three-neck round bottom flask. The solution was then heated at $300{ }^{\circ} \mathrm{C}$ for $1 \mathrm{~h}$ under argon atmosphere and cooled to room temperature with the heating source removed. After washing with excess ethanol, the resulting products were isolated by centrifugal separation and re-dispersed in hexane. To prepare core-shell MNP, iron (III) acetylacetonate (5.00 mmol) and manganese (II) chloride $(3.25 \mathrm{mmol})$ were placed in a $250 \mathrm{~mL}$ three-neck round bottom in the presence of oleylamine $(60.78 \mathrm{mmol})$, oleic acid $(15.84 \mathrm{mmol})$, and trioctylamine $(34.35 \mathrm{mmol})$. After injection of as-prepared seed nanoparticles $(80 \mathrm{mg})$ suspended in hexane $(4 \mathrm{~mL})$, the solution was heated at $350{ }^{\circ} \mathrm{C}$ for 1 $\mathrm{h}$ under argon atmosphere and cooled to room temperature, followed by washing with ethanol. The TEM analyses were performed using JEM 2100 at $200 \mathrm{kV}$ (Figure S1).
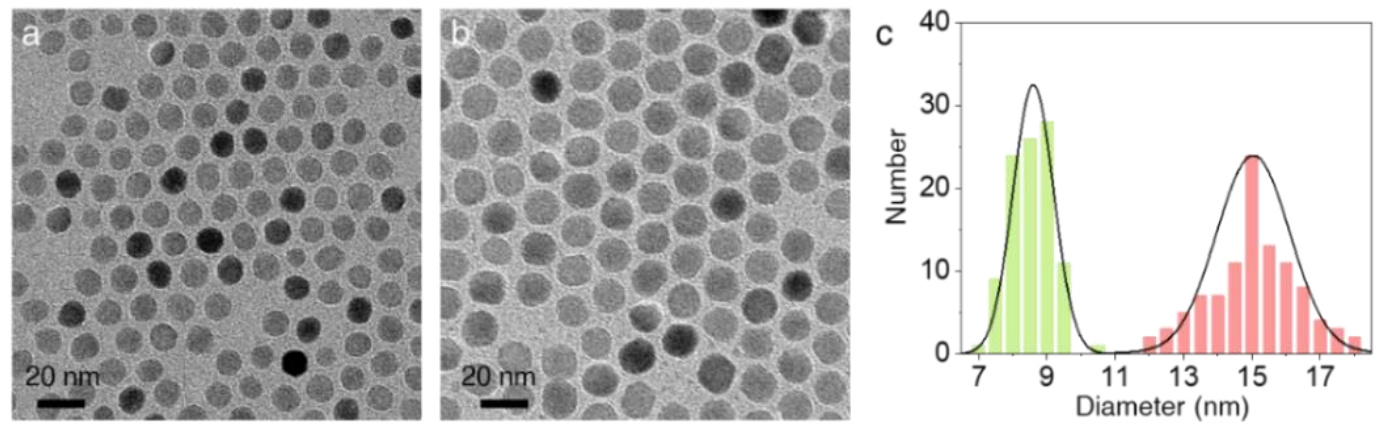

Figure S1. (a) TEM analysis of core $\mathrm{CoFe}_{2} \mathrm{O}_{4}$ nanoparticles with an average diameter of $8.8 \pm 0.6 \mathrm{~nm}$. (b) $\mathrm{CoFe}_{2} \mathrm{O}_{4} @ \mathrm{MnFe}_{2} \mathrm{O}_{4}$ core@shell nanoparticles with an average diameter of $15.34 \pm 1.40 \mathrm{~nm}$. (c) Size distribution of core nanoparticles and core@shell nanoparticles (total counts=100).

c. Synthesis of the MNP@PVP. MNP $(0.1 \mathrm{mg})$ suspended in toluene $(1 \mathrm{~mL})$ were mixed with $N$ vinylpyrrolidone $(3.00 \mathrm{mmol})$ as a monomer and $\operatorname{AIBN}(0.15 \mathrm{mmol})$ as an initiator, followed by being purged under an argon atmosphere for $10 \mathrm{~min}$ at room temperature. Then, the mixture solution was exposed to an alternative magnetic field (AMF) at $500 \mathrm{kHz}$ for $10 \mathrm{~min}$ using high-frequency induction heater (HF-10K, Taeyang Induction Heater Co., Korea). The solenoid type of coil was used for this purpose to generate a homogeneous magnetic field penetrating the solution in the vial. Using finite element method magnetics program, simulation result of the magnetic fields shows the nearly uniform magnetic field where the vial is placed (Figure S2). The resulting PVP is generally soluble in water because of a pyrrolin resonance structure, but it can also be dissolved in less polar solvents such as dioxane, acetone and toluene if produced in anhydrous environment. ${ }^{2}$ After isolation by centrifugation at 3,000 rpm for $5 \mathrm{~min}$, the resulting product was re-dispersed in deionized water (DIW). ${ }^{3}$ Also, The PVP thickness over the duration time of AMF was meausred. The PVP shell increased up to $3 \mathrm{~nm}$ within $10 \mathrm{~min}$ after which it reached a plateau and no further growth was observed (Figure S3). 


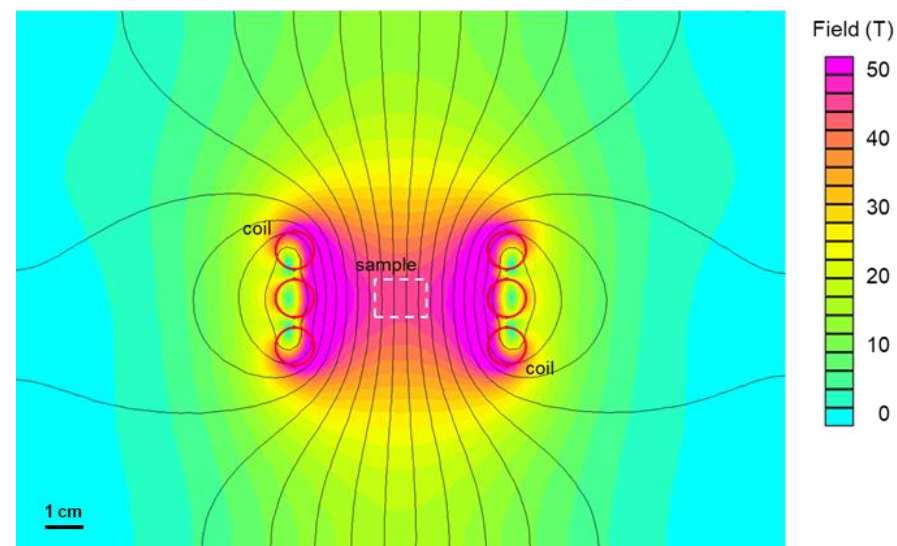

Figure S2. Simulation of the magnetic field around the coil at a $500 \mathrm{kHz}$ AC current with a $36.5 \mathrm{kA} / \mathrm{m}$. (red circle: copper coil, white box: sample solution in the vial).

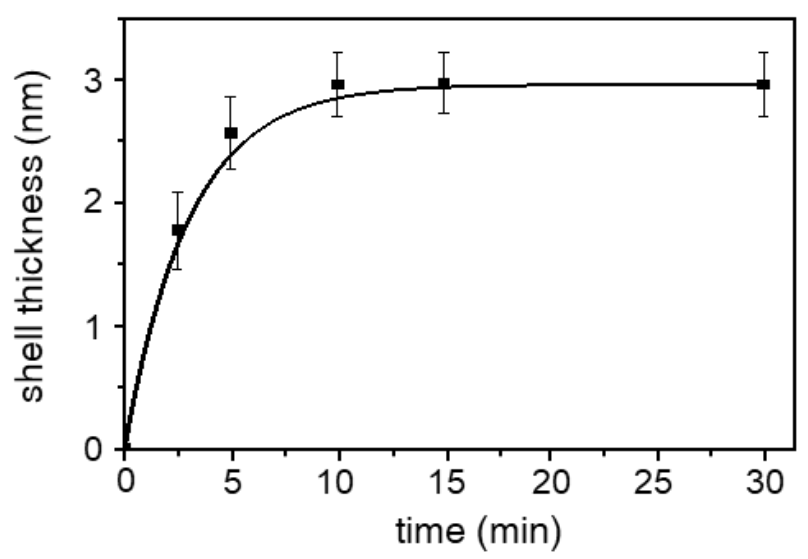

Figure S3. PVP shell thickness over the AMF duration time $(n=3)$. The maximum thickness is $3 \mathrm{~nm}$, because the temperature becomes less than $60^{\circ} \mathrm{C}$ at $>3 \mathrm{~nm}$ distance and the radical polymerization does not occur.

d. Fourier transform infrared (FT-IR) spectroscopy and thermal gravimetric analysis (TGA). FT-IR spectra of samples were measured using Vertex 70 spectrometer (Bruker, Germany). From the results (Figure S2a), chemical compositions of the PVP shell was identified by the characteristic peaks assigned as the $\mathrm{C}=\mathrm{O}$ and $\mathrm{C}-\mathrm{H}$ bending of the pyrrolidone group at $1,365 \mathrm{~cm}^{-1}$ and $1,465 \mathrm{~cm}^{-1}$, and bending and stretching vibration of $\mathrm{N}-\mathrm{C}=\mathrm{O}$ bonds at $650 \mathrm{~cm}^{-1}$ and $1,660 \mathrm{~cm}^{-1}$, respectively. ${ }^{7}$ For TGA, the measurement was performed using SDT Q600 (TA Instruments, USA). The weight loss of samples with increasing the temperature from 25 to $900{ }^{\circ} \mathrm{C}$ was measured with a heating rate of $10^{\circ} \mathrm{C} \mathrm{min}^{-1}$ under nitrogen atmosphere (Figure $\mathrm{S} 2 \mathrm{~b}$ ).

e. Long-term colloidal stability test for MNP@PVP. The average hydrodynamic diameter $\left(d_{\mathrm{H}}\right)$ of as-prepared MNP@PVP in various conditions of $\mathrm{pH}$ and salt concentration was measured by dynamic laser light scattering (DLS, Zetasizer Nano ZS, Malvern Instruments, UK). In the $\mathrm{pH}$ test, $10 \mathrm{mM}$ acetate and phosphate buffer solution were used for $\mathrm{pH} 4$ to 6 and $\mathrm{pH} 8$ to 10 , respectively. As for the salt test, an aqueous solution of $\mathrm{NaCl}$ with different concentration of 50 to $500 \mathrm{mM}$ was used.

f. Measurement of magnetic properties of MNP@PVP. To investigate the effect of polymeric shell on the magnetism of nanoparticles, field-dependent magnetization reversal of core MNP and PVP-coated MNP was characterized and compared to each other. The measurement was performed using a vibrating sample magnetometer (VSM) (7400S VSM, Lake Shore Cryotronics, USA) under maximum field strength of \pm 1.5 Tesla at room temperature. The unit of magnetization values, emu $/ \mathrm{g}_{\text {(metal) }}$, was determined by measuring the atomic mass of metal ions with an inductively coupled plasma mass spectrometer (ICP-MS) (NexION 300, 
PerkinElmer Inc., USA). The $M-H$ curves of both samples exhibited a single magnetic phase, without any phase separation or kinks in the graph. Also, they displayed the characteristics of superparamagnetism at room temperature, not showing significant changes in saturation magnetization of $c a .120 \mathrm{emu} / \mathrm{g}_{\text {(metal). }}$. These outcomes indicate that the chemical structures of metal atoms at the surface of the MNP were well preserved during the polymer coating process.

g. Characterization of MNP@PVP. A detailed compositional analysis for the was performed using FT-IR (Vertex 70 spectrometer, Bruker, Germany) and thermogravimetric analysis (TGA) (SDT Q600, TA Instruments, USA). In the FT-IR spectra, $\mathrm{PVP}$ is identified by the main bands assigned as the $\mathrm{C}=\mathrm{O}$ and $\mathrm{C}-\mathrm{H}$ bending of the pyrrolidone group at $1,365 \mathrm{~cm}^{-1}$ and $1,465 \mathrm{~cm}^{-1}$, respectively, as well as the bending and stretching vibration of the $\mathrm{N}-\mathrm{C}=\mathrm{O}$ bonds at $650 \mathrm{~cm}^{-1}$ and $1,660 \mathrm{~cm}^{-1}$, respectively. In TGA analysis, MNP exhibits a weight loss of approximately $2 \%$, which indicates surface ligand molecules. In the case of MNP@PVP, there are 2\% weight loss of surface ligands and $14.4 \%$ weight loss of PVP polymer. The remaining $83.6 \%$ indicates the weight of the MNP. $15 \mathrm{~nm}$ MNP has a volume of $1767 \mathrm{~nm}^{3}$ and a mass of $8.87 \times 10^{-18} \mathrm{~g}\left(\rho_{\mathrm{MNP}}=5.02 \mathrm{~g} / \mathrm{cm}^{3}\right)$. Since nanoparticle is analyzed to take about 83.6 weight $\%$ in TGA, relative polymer weight of $14.4 \%$ corresponds to a mass of $1.50 \times 10^{-18} \mathrm{~g}$ and a volume of $1246 \mathrm{~nm}^{3}\left(\rho_{\mathrm{PVP}}=1.20 \mathrm{~g} / \mathrm{cm}^{3}\right)$. This volume corresponds to $\sim 1.5 \mathrm{~nm}$ thick polymer shell, which is close to the TEM result.
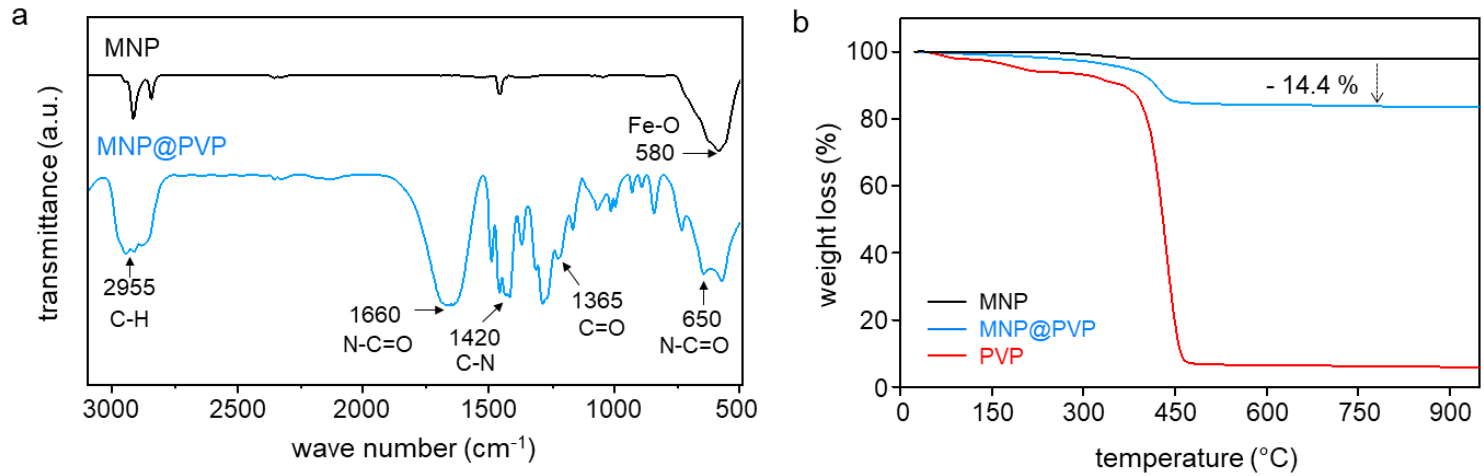

Figure S4. (a) FT-IR spectra of core MNP (black line) and MNP@PVP (blue line). (b) TGA curves of core MNP, MNP@PVP, and PVP (red line).

h. Chain length of PVP. We determined the average chain length and molecular weights of PVP from TEM and TGA analyses for MNP@PVP nanoparticle. The density of PVP shell is determined to be $1.203 \mathrm{~g} / \mathrm{cm}^{3}$ which from the PVP has a mass of $1.50 \times 10^{-18} \mathrm{~g}(14.4$ weight $\%$ of a nanoparticle $)$ and a volume of $1246 \mathrm{~nm}^{3}$. Since PVP density is linearly proportional to the molecular weight, ${ }^{4}$ our PVP single strand has $\sim 70$ chain length with molecular weight of $\sim 7,800 \mathrm{~g} / \mathrm{mol}$ in average. This value is cross-confirmed by estimating the initial concentration of radical initiators. From the estimating the concentration of radical initiators surrounding nanoparticles and the numbers of functional groups per nanoparticle, $\sim 120$ initiators and the total $\sim 7.7 \times 10^{3}$ monomer units are in $1 \mathrm{~nm}$ distance from the surface (see the Supporting Information 4). The chain length of 64 is close to the value obtained from the polymer density measurement. 


\section{Simulation of nanoscale heat transfer around the MNP}

a. Magnetically induced heat from the MNP. Applied magnetic field $(\mathrm{H}=50 \mathrm{mT}, f=500 \mathrm{kHz})$ and diameter of particle $(d=15 \mathrm{~nm})$ used in our experiment are below the nonlinear response regime $(\xi>1)$, despite the superparamagnetic properties. ${ }^{5}$ Under the nonlinear response regime, the magnetization follows the magnetic spin rotation changes quadratically with the applied AMF. ${ }^{6}$ The heat, which is the flow of thermal energy from the MNP after absorbing the magnetic energy, is generated as a pulse with $1000 \mathrm{~ns}$ period $(=500 \mathrm{kHz})$. The dimensionless parameter $\xi$ was introduced by Carrey to indicate the limit of validity of the LRT. ${ }^{7}$

$$
\xi=\mu_{0} M V H / k_{\mathrm{B}} T
$$

where $\mu_{0}$ is the permeability of free space $\left(4 \pi \times 10^{7} \mathrm{~T} \cdot \mathrm{m} / \mathrm{A}\right), M$ is the saturation magnetization, $V$ is the volume of the MNP $\left(1.77 \times 10^{-24} \mathrm{~m}^{3}\right)$, and $H$ is the $H$ : the applied field strength $(50 \mathrm{mT}, 40 \mathrm{kA} / \mathrm{m})$.

b. Maximum surface temperature of the MNP. To determine the surface temperature of the MNP, we applied the magnetic loss power $(P)$ of the MNP. In a nonlinear response regime, power of the MNP can be expressed as Eq. S2 and Eq. S3. ${ }^{8-9}$ The exponent $(\lambda)$ in Eq. S1 means relation between the magnetic loss power and the applied field strength, and is generally known as 2.3 for $15 \mathrm{~nm}$ iron oxide nanoparticles. ${ }^{10}$ The relaxation time $(\tau)$ was obtained from consideration of Neel relaxation and Brownian relaxation using Eq. S4-6. ${ }^{6}$

$$
\begin{aligned}
& P(H, f)=\pi \mu_{0} \chi^{\prime \prime} f H^{\lambda} \\
& \chi^{\prime \prime}=\frac{\mu_{0} M^{2} V}{k_{\mathrm{B}} T} \frac{2 \pi f \tau_{\mathrm{eff}}}{1+\left(2 \pi f \tau_{\mathrm{eff}}\right)^{2}} \\
& \tau_{\mathrm{eff}}=\frac{\tau_{\mathrm{N}} \tau_{\mathrm{B}}}{\tau_{\mathrm{N}}+\tau_{\mathrm{B}}} \\
& \tau_{\mathrm{N}}=\tau_{0} e^{\left(K V / k_{\mathrm{B}} T\right)} \\
& \tau_{\mathrm{B}}=\frac{3 \eta V_{\mathrm{H}}}{k_{\mathrm{B}} T}
\end{aligned}
$$

$P$ : the magnetic loss power $\left(\mathrm{W} / \mathrm{m}^{3}\right)$

$\mu_{0}$ : the permeability of free space $\left(4 \pi \times 10^{7} \mathrm{~T} \cdot \mathrm{m} / \mathrm{A}\right)$

$\chi^{\prime \prime}:$ the imaginary part of the susceptibility

$f:$ the AMF frequency $(500 \mathrm{kHz})$

$H$ : the applied field strength $(50 \mathrm{mT}, 40 \mathrm{kA} / \mathrm{m})$

$\lambda$ : the exponent

$M$ : the magnetic moment $\left(80 \mathrm{emu} / \mathrm{g}_{\mathrm{Fe}}, 304.08 \mathrm{kA} / \mathrm{m}\right)$

$V$ : the volume of the MNP $\left(1.77 \times 10^{-24} \mathrm{~m}^{3}\right)$

$k_{\mathrm{B}}$ : the Boltzmann constant $\left(1.38 \times 10^{-23} \mathrm{~J} / \mathrm{K}\right)$

$T$ : the temperature $(298.15 \mathrm{~K})$

$\tau_{\text {eff: }}$ the effective relaxation time

$\tau_{\mathrm{N}}$ : the Neel relaxation time

$\tau_{\mathrm{B}}$ : the Brownian relaxation time

$\tau_{0}$ : the attempt time $\left(10^{-9} \mathrm{~s}\right)$

$K$ : the magnetic anisotropy constant $\left(1.4 \times 10^{4} \mathrm{~J} / \mathrm{m}^{3}\right)$

$\eta$ : the viscosity $(0.56 \mathrm{mPa} \cdot \mathrm{s})$

$V_{\mathrm{H}}$ : the hydrodynamic volume of the MNP $\left(2.14 \times 10^{-24} \mathrm{~m}^{3}\right)$ 
The heat transport in nanoscale and in ultrafast time scale may differ significantly from the results of the classical Fourier law for diffusive heat transport and is described as quasi-ballistic radiative heat transport. Therefore, under ballistic regime where the mean free path of heat carrier is longer than the physical length scale of the system, heat flux from the MNP to the solution by blackbody radiative transfer should be considered (Eq. S7). ${ }^{11-}$ 12

$$
q=n^{2} \sigma\left(T_{\max }^{4}-T_{\mathrm{s}}^{4}\right)
$$

$q$ : the heat flux $\left(\mathrm{W} / \mathrm{m}^{2}\right)$

$n$ : the refreactive index of medium (toluene, 1.496)

$\sigma$ : the Stefan-Boltzmann constant $\left(5.67 \times 10^{-8} \mathrm{~W} / \mathrm{m}^{2} \mathrm{~K}^{4}\right)$

$T_{\max }$ : the maximum surface temperature of the MNP

$T_{\mathrm{s}}$ : the bulk solution temperature $(298.15 \mathrm{~K})$

Since $q$ is the heat flux which is rate of thermal energy transferred through a surface per unit of area and it is thermal energy generation rate per unit of volume in the above Eq. S2 and S7. Therefore, the obtained $T_{\max }$ is about $460 \mathrm{~K}\left(187^{\circ} \mathrm{C}\right)$.

c. MNP heating and cooling in solution. MNP is heated by thermal energy from magnetic energy and cooled by the solution through heat dissipation. The particle heating (Eq. S8) ${ }^{13-15}$ and cooling (Eq. S9) ${ }^{16-18}$ are expressed as:

$$
\begin{aligned}
& \text { Heating: } T(t)=273.15+\left(T_{\max }-T_{\mathrm{S}}\right)\left(1-e^{-t / \tau_{\mathrm{np}}}\right) \\
& \text { Cooling: } T(t)=273.15+\left(T_{\max }-T_{\mathrm{S}}\right) e^{-\left(t / \tau_{\mathrm{S}}\right)^{0.7}}
\end{aligned}
$$

$T(t)$ : the surface temperature of the MNP at time $t$

$T_{\mathrm{S}}$ : the bulk solution temperature $(298.15 \mathrm{~K})$

$\tau_{\mathrm{np}}: \frac{r^{2} \rho_{\mathrm{np}} C_{\mathrm{np}}}{k_{\mathrm{np}}}$, the transient time of the MNP $\left(2.0 \times 10^{-11} \mathrm{~s}\right)$

$r$ : the radius of the MNP $\left(7.5 \times 10^{-9} \mathrm{~m}\right)$

$\rho_{\text {np }}$ : the density of the MNP $\left(\mathrm{Fe}_{3} \mathrm{O}_{4}, 5180 \mathrm{~kg} / \mathrm{m}^{3}\right)$

$C_{\mathrm{np}}$ : the specific heat of the $\mathrm{MNP}\left(\mathrm{Fe}_{3} \mathrm{O}_{4}, 0.67 \mathrm{~J} / \mathrm{g} \cdot \mathrm{K}\right)$

$k_{\mathrm{np}}$ : the heat conductivity of the $\mathrm{MNP}\left(\mathrm{Fe}_{3} \mathrm{O}_{4}, 9.7 \mathrm{~W} / \mathrm{m} \cdot \mathrm{K}\right)$

$\tau_{\mathrm{S}}: \frac{r^{2} \rho_{\mathrm{S}} C_{\mathrm{S}}}{k_{\mathrm{S}}}$, the transient time of solution (toluene, $6.0 \times 10^{-10} \mathrm{~s}$ )

$\rho_{\mathrm{S}}$ : the density of solution (toluene, $867 \mathrm{~kg} / \mathrm{m}^{3}$ )

$C_{\mathrm{S}}$ : the specific heat of solution (toluene, $1.595 \mathrm{~J} / \mathrm{g} \cdot \mathrm{K}$ )

$k_{\mathrm{S}}$ : the heat conductivity of solution (toluene, $0.13 \mathrm{~W} / \mathrm{m} \cdot \mathrm{K}$ )

$t$ : time

These equations are plotted, and the results show that the surface temperature of MNP reaches to the highest point $\left(T_{\max }=460 \mathrm{~K}, 187^{\circ} \mathrm{C}\right.$ ) within $0.3 \mathrm{~ns}$, and cools down to its initial temperature (room temperature) within $\sim 10$ ns (Figure S3). 


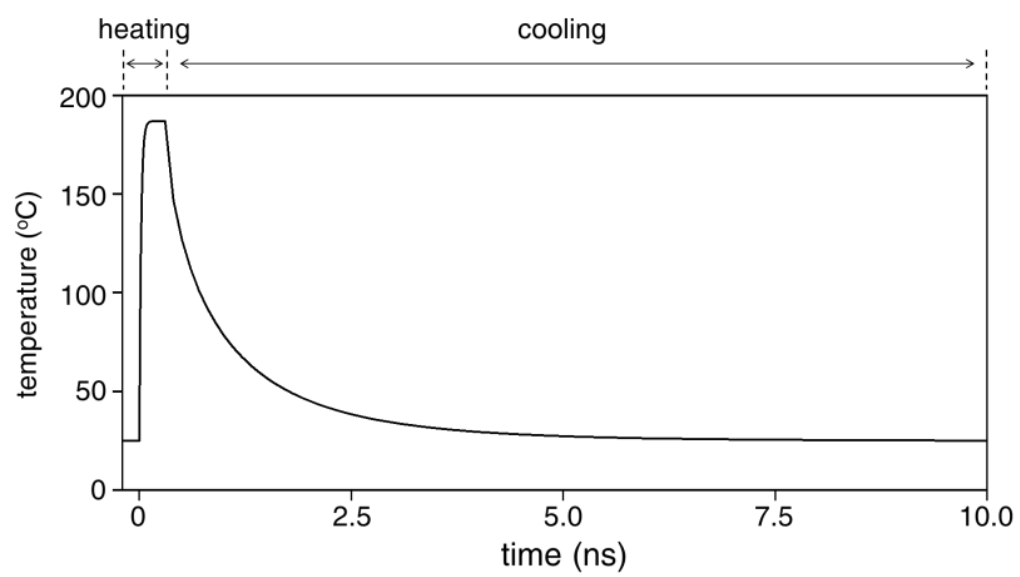

Figure S5. The simulated results exhibit that the surface temperature of the MNP reaches up to $460 \mathrm{~K}\left(187^{\circ} \mathrm{C}\right)$ of $0.3 \mathrm{~ns}$ after magnetic spin relaxation and cools down to $298.15 \mathrm{~K}\left(25^{\circ} \mathrm{C}\right)$ within $10 \mathrm{~ns}$.

d. Heat distribution around MNP. Heat distribution around MNP is calculated using with COMSOL Multiphysics. The heat propagation kinetics from the surface into solution are simulated using following equation (Eq. S10). ${ }^{19-21}$

$$
\frac{\partial T(r, t)}{\partial t}=\frac{k_{\mathrm{S}}}{\rho_{\mathrm{S}} C_{\mathrm{S}}} \frac{\partial^{2} T(r, t)}{\partial r^{2}}
$$

$T(r, t)$ : the temperature at the distance $r$ from the surface of the MNP at time $\mathrm{t}$.

$\rho_{\mathrm{S}}$ : the density of solution (toluene, $867 \mathrm{~kg} / \mathrm{m}^{3}$ )

$C_{\mathrm{S}}$ : the specific heat of solution (toluene, $1.595 \mathrm{~J} / \mathrm{g} \cdot \mathrm{K}$ )

$k_{\mathrm{S}}$ : the heat conductivity of solution (toluene, $0.13 \mathrm{~W} / \mathrm{m} \cdot \mathrm{K}$ )
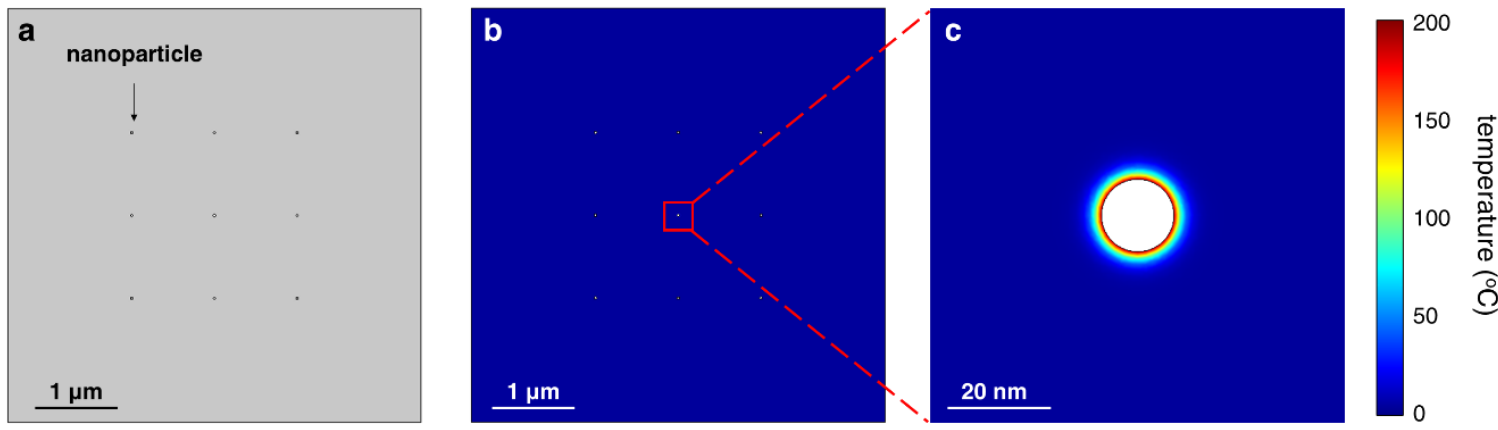

Figure S6. (a) Number of nanoparticles per area in simulation according to experimental concentration of 0.1 $\mathrm{mg} / \mathrm{mL}$. (b) Heat distribution of $0.3 \mathrm{~ns}$ after magnetic spin relaxation. (c) Magnified image of heat distribution around nanoparticle. 
e. Heat distribution around MNP under different strengths of magnetic fields. From the Eq. S1-S7, at different AMF strengths, nanoparticle surface temperature changes. ${ }^{8-10,22}$ Figure S5 shows the heat distribution around the MNP according to different strengths of magnetic fields (40, 45, and $50 \mathrm{mT})$. The obtained distances that reach AIBN activation temperatures above $60{ }^{\circ} \mathrm{C}$ were about 1,2 , and $3 \mathrm{~nm}$, at the AMF strengths of 40, 45 , and $50 \mathrm{mT}$, respectively. These values match well with the experimental polymerization results.
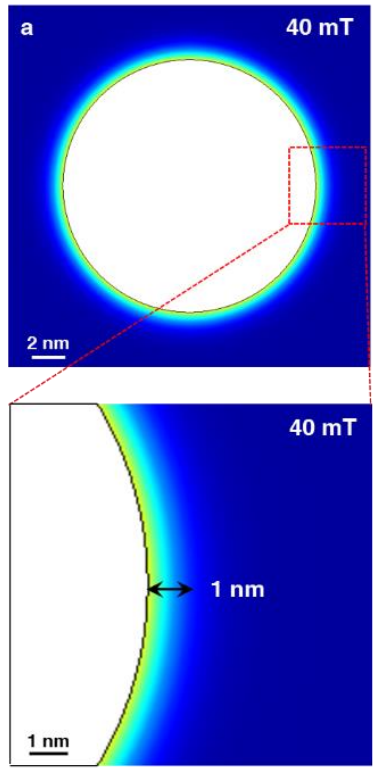
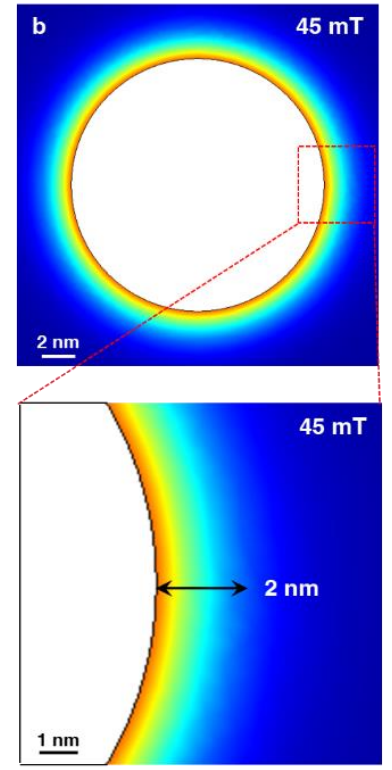
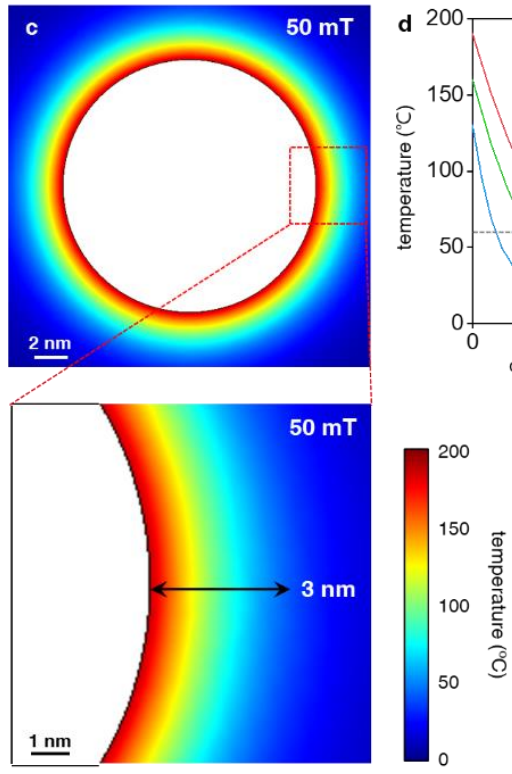

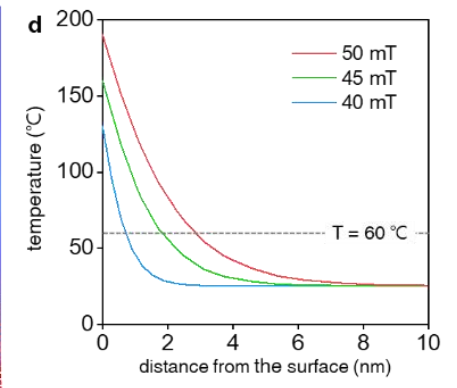

Figure S7. Heat distribution after magnetic spin relaxation under magnetic field of (a) $40 \mathrm{mT}$, (b) $45 \mathrm{mT}$, and (c) $50 \mathrm{mT}$. (d) Cross-sectional graph for heat distribution upon the distance from the surface of the MNP. 


\section{Comparison of bulk heating and local heating of MNP}

Bulk solution heating at $70{ }^{\circ} \mathrm{C} . \mathrm{MNP}(0.1 \mathrm{mg})$ dispersed in toluene $(1 \mathrm{~mL})$ were mixed with $N$-vinylpyrrolidone $(3.00 \mathrm{mmol})$ and AIBN $(0.15 \mathrm{mmol})$, and the mixture was purged with argon for $10 \mathrm{~min}$ at room temperature. Then, the mixture was put in the oil bath at $70{ }^{\circ} \mathrm{C}$ (AIBN initiation is between $60 \sim 120{ }^{\circ} \mathrm{C}$, with a half-life of $1 \mathrm{~h}$ at $70{ }^{\circ} \mathrm{C}$ ). The resulting product was isolated by centrifugation at 3,000 rpm for $5 \mathrm{~min}$ and re-dispersed in DIW (Figure S6a).

Incubating with stirring at room temperature. MNP $(0.1 \mathrm{mg}), N$-vinylpyrrolidone $(3.00 \mathrm{mmol})$ and AIBN $(0.15 \mathrm{mmol})$ were dispersed in toluene $(1 \mathrm{~mL})$ and purged with nitrogen for $10 \mathrm{~min}$ at room temperature. After 10 min of incubation with stirring at room temperature, the products were precipitated by centrifugation and redispersed in DIW (Figure S6b).

The bulk solution temperature during AMF heating. MNP $(0.1 \mathrm{mg})$ dispersed in toluene $(1 \mathrm{~mL})$ were mixed with $N$-vinylpyrrolidone $(3.00 \mathrm{mmol})$ and AIBN $(0.15 \mathrm{mmol})$, and the mixture was purged with argon for 10 min at room temperature. Then, the mixture was put in the coil under an AMF of $50 \mathrm{mT}$ at $500 \mathrm{kHz}$. The timedependent temperature curves are measured using a fiber optic thermometer (M602, Lumasense technologies, Inc. USA) under AMF magnetic heating. The Experiments were repeated three times for all samples. The bulk solution temperature remained constantly at room temperature $\left(\Delta \mathrm{T}<3{ }^{\circ} \mathrm{C}\right.$, Figure $\left.\mathrm{S} 7\right)$.
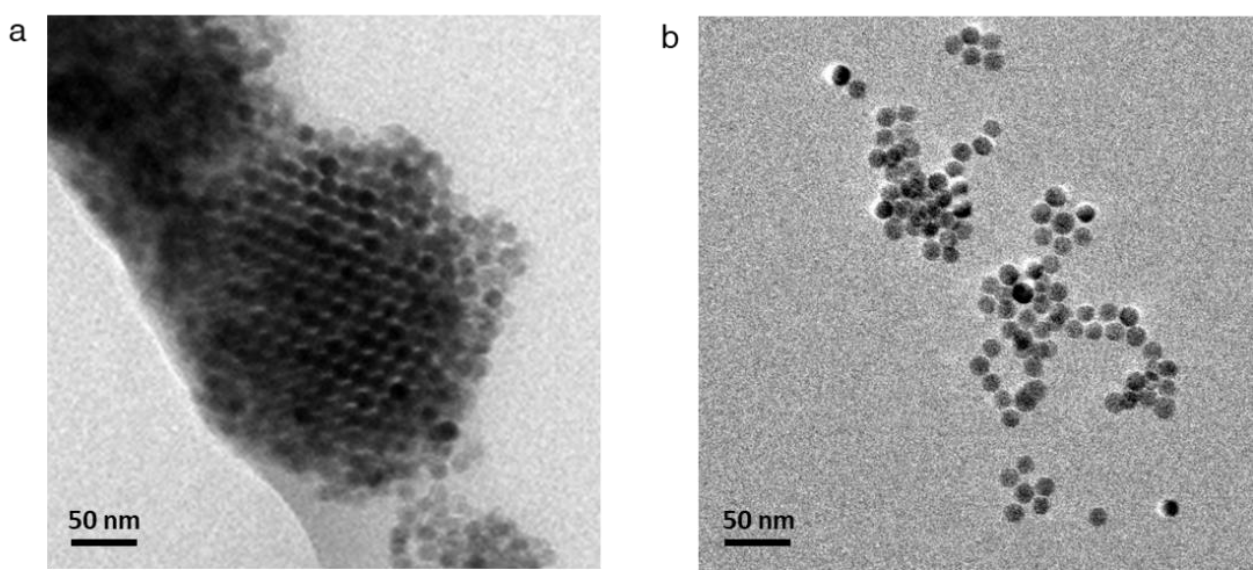

Figure S8. (a) The bulk solution heating at $70{ }^{\circ} \mathrm{C}$ yields a multi nanoparticle-embedded PVP polymeric matrix. (b) The incubation of the mixture with stirring at room temperature does not induce polymerization.

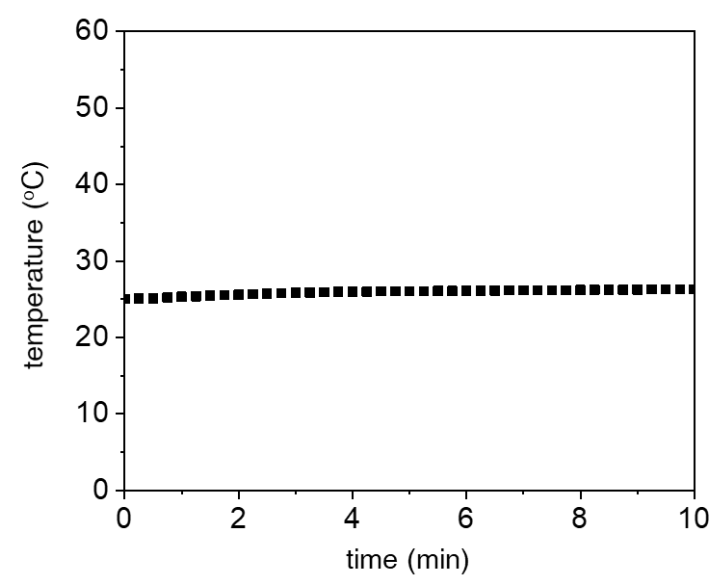

Figure S9. The bulk solution temperature as a function of time for MNP under an AMF of $50 \mathrm{mT}$ at $500 \mathrm{kHz}$. 


\section{Versatile surface polymerization of the MNP}

Chemicals. $N$-(2-aminoethyl) methacrylamide hydrochloride (AEM) and chloromethyl styrene (CMS) were purchased from Polysciences, acrylic acid (AA), glycidyl methacrylate (GMA), $N, N$ '-bis(acryloyl)cystamine (BAC), benzoyl peroxide (BPO, 75\%), azobisisobutyronitrile (AIBN, $0.2 \mathrm{M}$ in toluene), dimethyl sulfoxide (DMSO, 99.5\%), dimethylformamide (DMF, 99.8\%), diethyl ether (99.9\%), toluene (99.8\%), ethanol (99.5\%), methanol (99.8\%), dichloromethane (DCM, 99.8\%), tetrahydrofuran (THF, 99.9\%) and dithiothreitol (DTT, 99\%) were purchased from Sigma-Aldrich.

\section{Synthesis of versatile surface-polymerized MNP.}

MNP@PAEM. MNP $(0.1 \mathrm{mg})$ suspended in DMSO $(1 \mathrm{~mL})$ were mixed with AEM (2.40 mmol) as a monomer and AIBN $(0.15 \mathrm{mmol})$ as an initiator, followed by being purged under an argon atmosphere for $10 \mathrm{~min}$ at room temperature. Then, the mixture solution was exposed to an AMF of $40 \mathrm{mT}$ at $500 \mathrm{kHz}$ for $5 \mathrm{~min}$. The resulting product was isolated by centrifugation at 3,000 rpm for $5 \mathrm{~min}$ and re-dispersed in DIW.

MNP@PAA. MNP $(0.1 \mathrm{mg})$, AA $(3.00 \mathrm{mmol})$ and BPO $(0.30 \mathrm{mmol})$ were dispersed in $1 \mathrm{~mL}$ of THF, and purged with nitrogen for $10 \mathrm{~min}$ at room temperature. After applying an AMF of $40 \mathrm{mT}$ at $500 \mathrm{kHz}$ for $10 \mathrm{~min}$, the resulting product was precipitated by centrifugation at 3,000 rpm for $5 \mathrm{~min}$, and filtered off with excess diethyl ether and methanol. As-prepared particles were then re-dispersed in DIW.

MNP@PCMS. MNP $(0.1 \mathrm{mg})$, CMS $(4.70 \mathrm{mmol})$, and BPO $(0.16 \mathrm{mmol})$ were immersed in $1 \mathrm{~mL}$ of toluene and heated by an AMF of $40 \mathrm{mT}$ at $500 \mathrm{kHz}$ for $10 \mathrm{~min}$. Then, excess ethanol was added to the solution for precipitation of the products with centrifugation at 3,000 rpm for $5 \mathrm{~min}$. The obtained MNP was re-dispersed in toluene.

MNP@PGMA. MNP $(0.1 \mathrm{mg})$ suspended in DMF $(1 \mathrm{~mL})$ were added with GMA $(3.00 \mathrm{mmol})$ and AIBN $(0.13$ mmol). Then, the solution was purged with argon for $10 \mathrm{~min}$ and applied to an AMF of $40 \mathrm{mT}$ at $500 \mathrm{kHz}$ for $10 \mathrm{~min}$. After adding excess methanol and centrifuging at 3,000 rpm for $5 \mathrm{~min}$, the obtained precipitate was collected and re-dispersed in small amount of DCM. This process was repeated three time and final products were suspended in THF (or toluene).

MNP@PBAC. Solution of DMSO (1 mL) containing the core MNP $(0.1 \mathrm{mg})$, BAC (3.60 mmol), and AIBN $(0.20 \mathrm{mmol})$ was prepared and heated by an AMF of $40 \mathrm{mT}$ at $500 \mathrm{kHz}$ for $10 \mathrm{~min}$. The resulting particles were washed with DIW under sonication and precipitated by centrifugation at 3,000 rpm for $3 \mathrm{~min}$. Continuously, to make the thiol functional groups available, the disulfide bonds of PBAC were cleaved by incubating the resulting MNP in DTT solution with a concentration of $0.3 \mathrm{mM}$ for $10 \mathrm{~min}$. The final products were isolated by centrifugation with a membrane filter (molecular weight cutoff, $100 \mathrm{KDa}$ ) and re-dispersed in DIW.

Colloidal stability of versatile polymer-coated MNP. The average hydrodynamic diameter $\left(d_{\mathrm{H}}\right)$ of versatile surface-polymerized MNP was measured by dynamic laser light scattering (DLS, Zetasizer Nano ZS, Malvern Instruments, UK). The slight increase in the hydrodynamic size from $16 \mathrm{~nm}$ to $21 \mathrm{~nm}$, to $22 \mathrm{~nm}$, to $24 \mathrm{~nm}$, to 24 nm, to 25 nm are observed for MNP@PAEM, MNP@PAA, MNP@PCMS, MNP@PGMA, MNP@PBAC, compared to the original MNP. 

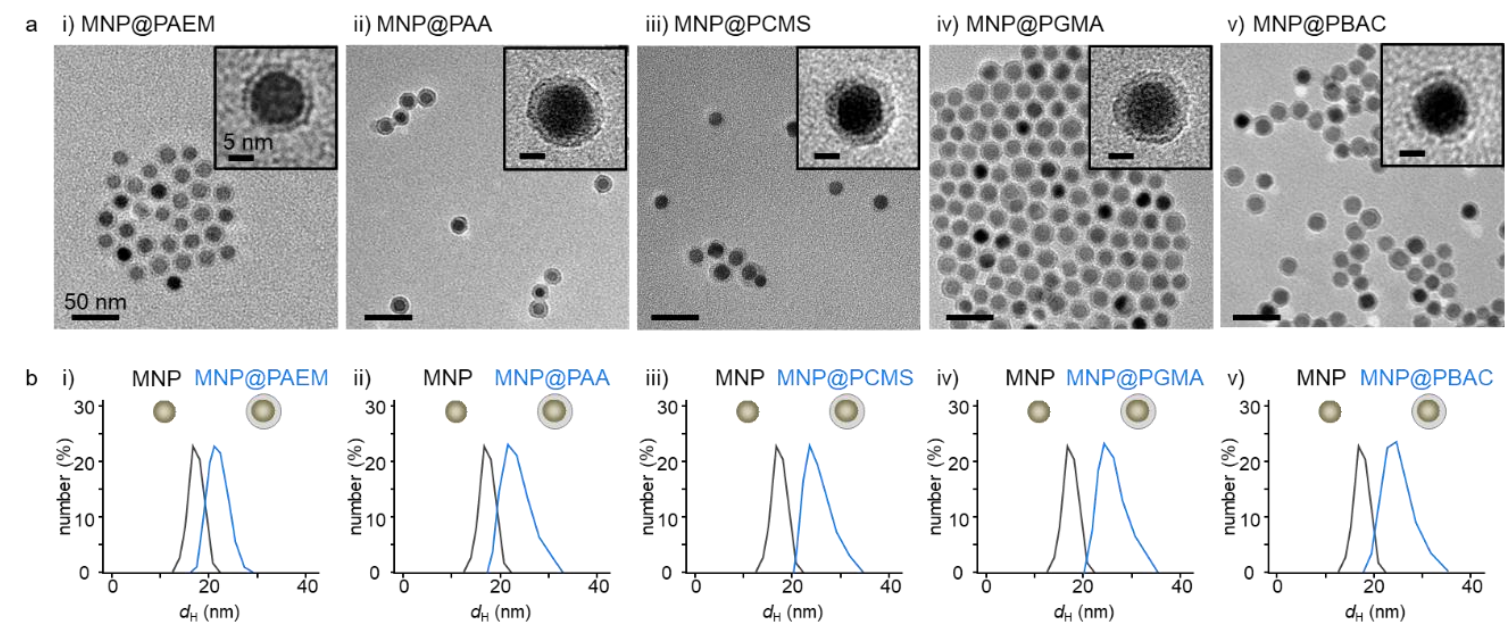

Figure S10. (a) Low magnification TEM images and (b) hydrodynamic size $\left(d_{\mathrm{H}}\right)$ of versatile polymer-coated MNP: (i) PAEM, (ii) PAA, (iii) PCMS, (iv) PGMA, and (v) PBAC.

Characterization of versatile polymer-coated MNP. A detailed compositional analysis for the as-prepared various polymeric MNP was performed using FT-IR (Vertex 70 spectrometer, Bruker, Germany) and TGA (SDT Q600, TA Instruments, USA). For the MNP@PAEM, the characteristic peaks of a polymeric shell were identified at $1,155 \mathrm{~cm}^{-1}, 1,635 \mathrm{~cm}^{-1}, 1,725 \mathrm{~cm}^{-1}$, and 3,450 $\mathrm{cm}^{-1}$, which correspond to the C-N stretch, $\mathrm{N}-\mathrm{H}$ bend, $\mathrm{C}=\mathrm{O}$ stretch and N-H stretch, respectively. ${ }^{23}$ For the MNP@PAA, prominent bands associated with $\mathrm{C}=\mathrm{O}$ and $\mathrm{C}$ O stretch were confirmed at $1,715 \mathrm{~cm}^{-1}$ and $1,200-1,315 \mathrm{~cm}^{-1}$, respectively. The broad $\mathrm{O}-\mathrm{H}$ stretch were observed at 3,000 $\mathrm{cm}^{-1}$ superimposed on the stretching bands of $\mathrm{CH}$ and $\mathrm{CH}_{2}$ at $3,100-2,850 \mathrm{~cm}^{-1}$. The bands at $795 \mathrm{~cm}^{-1}$ and $1,450-1,400 \mathrm{~cm}^{-1}$ were associated with an out-of-plane deformation of $\mathrm{OH}^{\cdots} \mathrm{O}$ hydrogen bonds and in-plane deformation of C-O-H bonds, respectively. Meanwhile, broad band between $2,710 \mathrm{~cm}^{-1}$ and $1,450 \mathrm{~cm}^{-1}$ was assigned to overtones. ${ }^{24}$ For the MNP@PCMS, the C-H stretch in aromatics and overtone band related to the substitution pattern of benzene ring were observed at 3,100-3,000 $\mathrm{cm}^{-1}$ and $200-1,650 \mathrm{~cm}^{-1}$, respectively. The skeletal vibration from $\mathrm{C}=\mathrm{C}$ stretch in aromatics was confirmed at 1,600-1,585 and 1,500-1,400 $\mathrm{cm}^{-1}$. The peaks of C-H bend in aromatics appeared at $1,250-1,000 \mathrm{~cm}^{-1}$ and $760-690 \mathrm{~cm}^{-1}$ for in-plane (weak) and out-plane (strong) configuration, respectively. Also, the $\mathrm{C}-\mathrm{H}$ wagging and $\mathrm{C}-\mathrm{Cl}$ stretching vibration of alkyl halide group were observed at 1,300-1,150 and 760-600 $\mathrm{cm}^{-1}$, respectively. ${ }^{25}$ For the MNP@PGMA, the characteristic peaks from the stretching vibration of oxirane groups were identified at 1,265, 906, 850 and $760 \mathrm{~cm}^{-1}$. The bands associated with $\mathrm{C}-\mathrm{O}$ and $\mathrm{C}=\mathrm{O}$ stretch of ester groups were also observed at 1,390-1,340 $\mathrm{cm}^{-1}$ and 1,735 $\mathrm{cm}^{-1}$, respectively. ${ }^{26}$ For the $\mathrm{MNP} @ \mathrm{PBAC}$, the characteristics bands of $\mathrm{C}=\mathrm{O}$ and $\mathrm{N}-\mathrm{H}$ bonds in amide groups were confirmed at $1,640 \mathrm{~cm}^{-1}$ and $1,525 \mathrm{~cm}^{-1}$, respectively. ${ }^{27}$

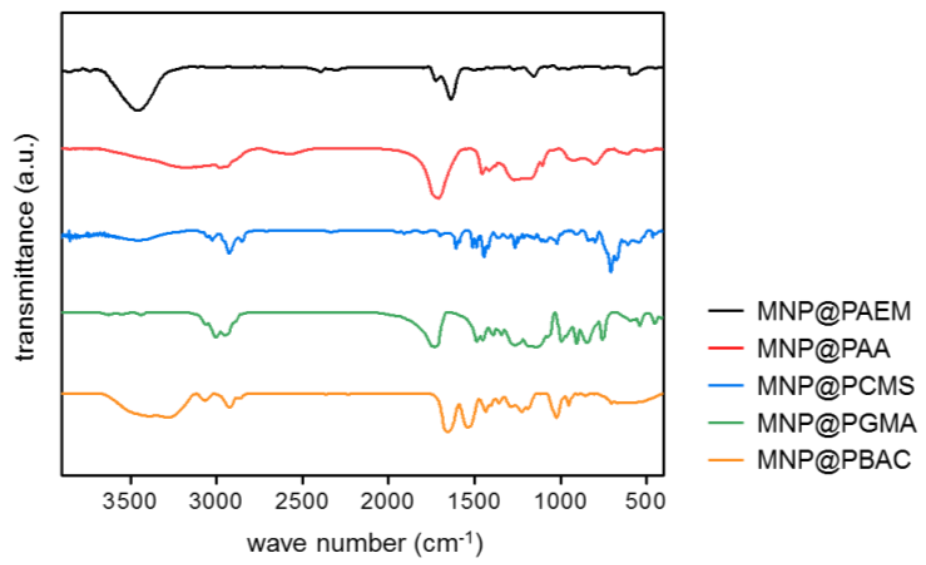

Figure S11. FT-IR spectra of versatile polymer-coated MNP. Each MNP shows characteristic IR peaks of either PAEM (blue), PAA (red), PCMS (blue), PGMA (green), or PBAC (orange). 


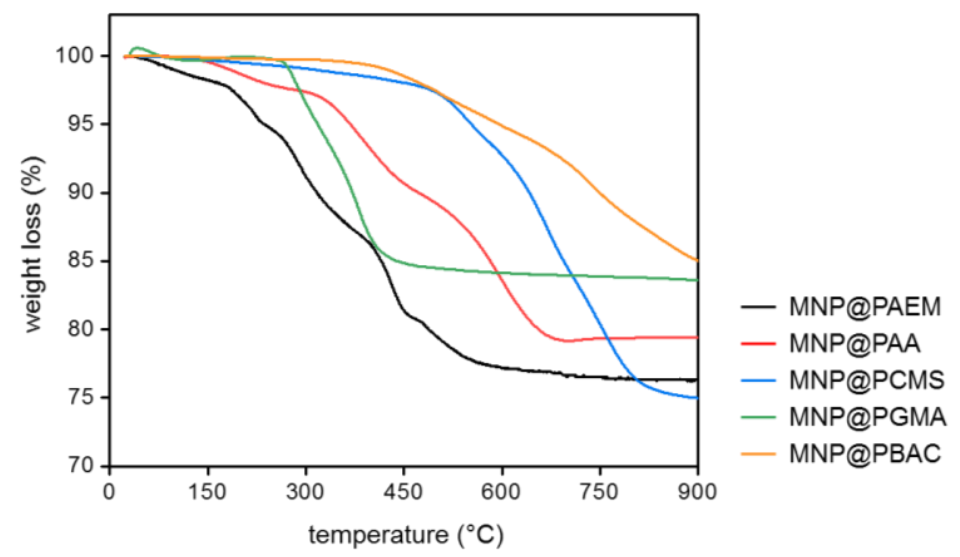

Figure S12. TGA curves of versatile surface-polymerized MNP, measured at temperature from 30 to $900^{\circ} \mathrm{C}$ with a heating rate of $10^{\circ} \mathrm{C} \mathrm{min}{ }^{-1}$ under nitrogen atmosphere. The thermal decomposition weight loss patterns of each sample were well-matched with previously reported values. Reference 28, 29, 30, 31, and 32 for PAEM, PAA, PCMS, PGMA, and PBAC, respectively.

Quantification of amine functional group MNP@PAEM. The $\mathrm{NH}_{2}$ loading was found by the Kaiser test assay (ninhydrin assay). ${ }^{33}$ Three solutions were prepared: (i) phenol solution ( $\sim 80 \%$ in ethanol), (ii) $\mathrm{KCN}$ solution in $\mathrm{H}_{2} \mathrm{O}$ /pryidine, (iii) ninhydrin solution ( $6 \%$ in ethanol). The sample was placed in the test tube, then, $75 \mu \mathrm{L}$ of solution (i), $100 \mu \mathrm{L}$ of solution (ii), and $75 \mu \mathrm{L}$ of solution (iii) were added to test tube. The mixture was sonicated for $5 \mathrm{~min}$, then, diluted with $4.75 \mathrm{~mL}$ of $60 \% \mathrm{EtOH}$. After centrifugation, the supernatant was analyzed by UV-Vis spectroscopy at $570 \mathrm{~nm}$.

$$
\mathrm{NH}_{2}\left(\frac{\mu \mathrm{mol}}{\mathrm{g}}\right)=\frac{\left(A b s_{\text {sample }}-A b s_{\text {blank }}\right) \times \text { dilution factor }(\mathrm{mL}) \times 10^{6}}{\varepsilon \times \text { sample weight }(\mathrm{mg})}
$$

The dilution factor is $5 \mathrm{~mL}$ and extinction coefficient $(\varepsilon)$ is $15000 \mathrm{~L} \cdot \mathrm{mol}^{-1} \mathrm{~cm}^{-1}$. The number of amine functional groups of MNP with $1 \mathrm{~nm}$ thick polymer shell exhibited $\sim 7.7 \times 10^{3}$ amine groups using from the Eq. S11. When shell thickness was changed from 1 to $3 \mathrm{~nm}$, the surface area increased 1.5-fold and the number of amine functional groups were increased accordingly (Figure S11).

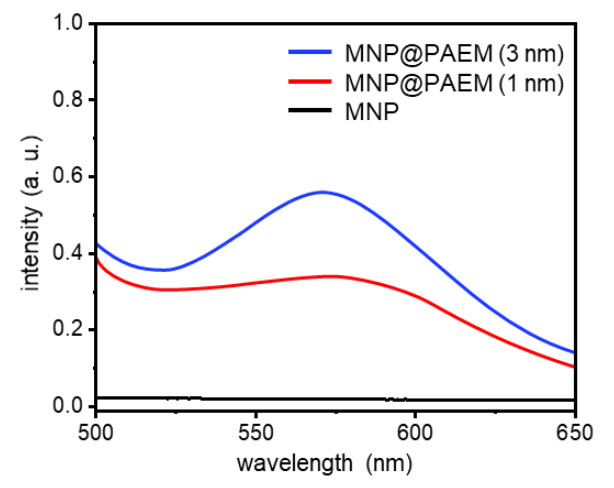

Figure S13. UV-Vis adsorption spectra of the MNP (black line), $1 \mathrm{~nm}$ thick PAEM-coated MNP (red line), and $3 \mathrm{~nm}$ thick PAEM-coated MNP (blue line). 


\section{Quantitative analysis of co-polymerization}

Preparation of three different monomers labeled with dye molecules. Three monomers labeled with different dyes of Alexa Fluor 405 (Ex 402 nm, Em 421 nm; blue-colored, m) ), Alexa Fluor 488 (Ex 495 nm, Em 519 nm; green-colored, $\mathrm{m}_{2}$ ) and Alexa Fluor $594\left(\mathrm{Ex} 590 \mathrm{~nm}, \mathrm{Em} 617 \mathrm{~nm}\right.$; red-colored, $\mathrm{m}_{3}$ ) were prepared by coupling chemistry between amine groups of AEM monomer and $N$-hydroxysuccinimide (NHS) ester groups of each dye molecules as follows: AEM $(0.27 \mathrm{mmol})$ dissolved in $10 \mathrm{mM}$ phosphate buffer $(70 \mu \mathrm{L})$ was added with $30 \mu \mathrm{l}$ of DMSO solution containing $2 \mu \mathrm{mol}$ of Alexa Fluor 405 (or 488 or 594), and maintained for $2 \mathrm{~h}$ at room temperature. The resulting products were washed and collected using a high-performance liquid chromatography method.

Construction of calibration curves for fluorescence analysis of multivalent nano-surfaces. To make a calibration curve for the fluorescence intensity versus the number of fluorophores contained in the polymer shell, the quenching effect of the MNP on the quantum yield was estimated in advance. At first, with a use of $\mathrm{m}_{1}, \mathrm{~m}_{2}$, and $\mathrm{m}_{3}$ as a monomer, the MNP coated with polymers (poly- $\mathrm{m}_{1}$, poly- $\mathrm{m}_{2}$, and poly- $\mathrm{m}_{3}$, respectively) were prepared as follows: the DMSO solution containing MNP $(18 \mathrm{nM})$, monomers $(0.23 \mathrm{mM})$, and AIBN $(0.02 \mathrm{mM})$ was purged under an argon atmosphere for $10 \mathrm{~min}$ and exposed to an AMF of $45 \mathrm{mT}$ at $500 \mathrm{kHz}$ for $15 \mathrm{~min}$. The resulting products were isolated by magnetic separation using MACS columns and the number of fluorophores included in the polymer shell was determined by subtracting the fluorescence intensity of the eluent from that of the initial synthesis solution. Then, the quenching efficiency of the MNP was evaluated by comparing the fluorescence quantum yield of polymer-coated MNP and the same moles of free monomers. The quantum yield, which was defined as the ratio of the number of photons emitted to the number of photons absorbed, was calculated according to the following equation (Eq. S12):

$$
\Phi_{S}=\Phi_{R} \frac{I_{S}}{I_{R}} \frac{A_{R}}{A_{S}} \frac{\eta_{S}^{2}}{\eta_{R}{ }^{2}}
$$

where $\Phi$ is the quantum yield, $I$ is the integrated area under the emission spectrum, $A$ is the absorbance at the excitation wavelength and $\eta$ is the refractive index of the solvent. The subscripts $\mathrm{S}$ and $\mathrm{R}$ refer to the sample and reference, respectively. The steady-state fluorescence study was performed with a spectrofluorometer (FluoroMax Plus, Horiba, Japan), and the absorption spectrum was recorded with a UV-Vis spectrophotometer (V760, JASCO, USA), while keeping the absorbance maximum values below 0.1 to avoid re-absorption effects. Quinine sulfate in $0.1 \mathrm{M} \mathrm{H}_{2} \mathrm{SO}_{4}$ solution $\left(\Phi_{\mathrm{R}}=54 \%, \eta=1.33\right)$ was used as a standard for $\mathrm{m}_{1}$, and fluorescein in $0.1 \mathrm{M} \mathrm{NaOH}$ solution $\left(\Phi_{\mathrm{R}}=95 \%, \eta=1.33\right.$ ) was used as a standard for $\mathrm{m}_{2}$ and $\mathrm{m}_{3}$. After being coated onto MNP surfaces, the quantum yield of each monomer was found to be decreased from $67.5 \%, 87.3 \%$, and $74.5 \%$ to $28.8 \%, 40.5 \%$, and $38.5 \%$, indicating the quenching efficiency of $57.7 \%, 53.6 \%$ and $48.3 \%$ for $\mathrm{m}_{1}, \mathrm{~m}_{2}$, and $\mathrm{m}_{3}$, respectively. The calibration curves for the fluorescence intensity constructed with a consideration of quenching efficiency for each fluorophore were presented as below.

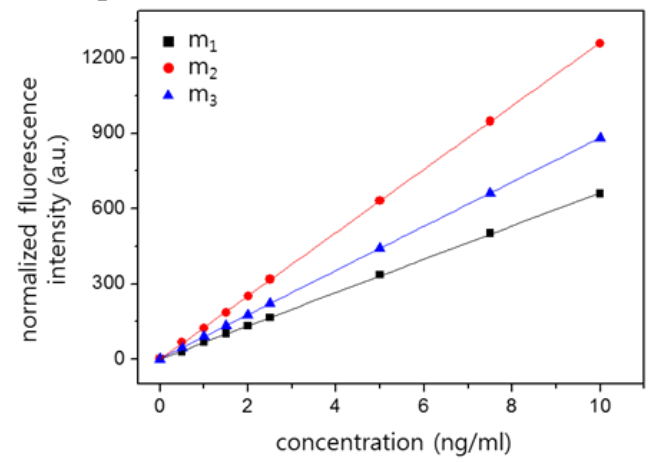

Figure S14. The calibration curves for the normalized fluorescence intensity versus the concentration of each polymeric component (i.e., poly- $\mathrm{m}_{1}$, poly- $\mathrm{m}_{2}$, poly- $\mathrm{m}_{3}$ ) in the copolymer shell. 


\section{Charge-dependent cell binding of the MNP}

Preparation of folic acid and Alexa Fluor 594 conjugated MNP with different surface charges. The AEMfolate conjugate was synthesized by coupling the carboxylic acid group of the folic acid with the amine group of AEM. The monomers labeled with dyes of Alexa Fluor 594 (Ex 590 nm, Em 617 nm; red-colored) were prepared by coupling chemistry between amine groups of AEM monomer and NHS ester groups of each dye molecules as mentioned above. For neutral charge MNP (0.1 mg), AEM (1.20 mmol), AA (0.90 mmol), BPO (0.01 mmol), AEM-folate $(0.45 \mathrm{mmol})$ and AEM- Alexa Fluor $594(0.45 \mathrm{mmol})$ were dispersed in $1 \mathrm{~mL}$ of THF, and purged with nitrogen for $10 \mathrm{~min}$ at room temperature. After applying an AMF of $45 \mathrm{mT}$ at $500 \mathrm{kHz}$ for 10 min, the resulting product was precipitated by centrifugation at 3,000 rpm for $5 \mathrm{~min}$ and re-dispersed in DIW.

Cell culture. HeLa (human cervical cancer, folate positive cell lines) and A549 cells (folate negative cell lines) were obtained from American Type Culture Collection and cultured in RPMI 1640 supplemented with heatinactivated $10 \%(\mathrm{v} / \mathrm{v})$ fetal bovine serum and $1 \%(\mathrm{v} / \mathrm{v})$ antibiotic-antimycotic solution. Cells were cultured in 8 well-chambered cell culture slides and maintained in a humidified atmosphere of $5 \% \mathrm{CO}_{2}$ incubator at $37{ }^{\circ} \mathrm{C}$.

MNP treatment. $1 \%$ bovine serum albumin (BSA) in 1X phosphated buffered saline (PBS) was applied to cell and incubated for 1 hour at $37{ }^{\circ} \mathrm{C}$. Cells were carefully rinsed 3 times with 1X PBS. $200 \mu \mathrm{L}$ of the MNP $(0.2$ $\mathrm{mg} / \mathrm{mL}$ ) with different surface charge (from $-20 \mathrm{mV}$ to $20 \mathrm{mV}$ ) was treated to cells. After 1 hour, samples were washed with $1 \mathrm{X}$ PBS three times.

Quantification specific binding of the MNP to cell surface. Before fluorescence imaging, cells were fixed in $4 \%$ paraformaldehyde for $30 \mathrm{~min}$. After treating mounting solution (ProLong ${ }^{\circledR}$, Thermo Fisher scientific), cells were observed by fluorescence microscopy (Eclips Ti-U, Nikon). For the fluorescence image acquisition, the Electron Multiplying Charge-Coupled Device (EMCCD, iXon 897, Andor) was utilized. All images were acquired in same imaging condition. Fluorescence intensity of the MNP bound cells were measured by NISElements (Nikon). The efficiency of specific cell targeting was estimated by measuring the fluorescence intensity ratio between folic acid labeled MNP and non-labeled MNP treated cells.

Binding of the MNP to folate negative cells (A549 cell line). To show the specific targeting capability of the synthesized MNPs, the MNP targeting efficiency is tested with folate negative A549 cell line. Although A549 cells show little expression of folate receptor, positively charged nanoparticles exhibit higher FL intensity compared to that of the negatively charged and zwitterionic nanoparticles regardless the surface targeting moiety (Figure S13a, b). As a result, the negatively charged and zwitterionic nanoparticles have low non-specific effects, but the positively charged nanoparticles have high non-specific binding due to charge attraction between the surface of particles and cell membrane.
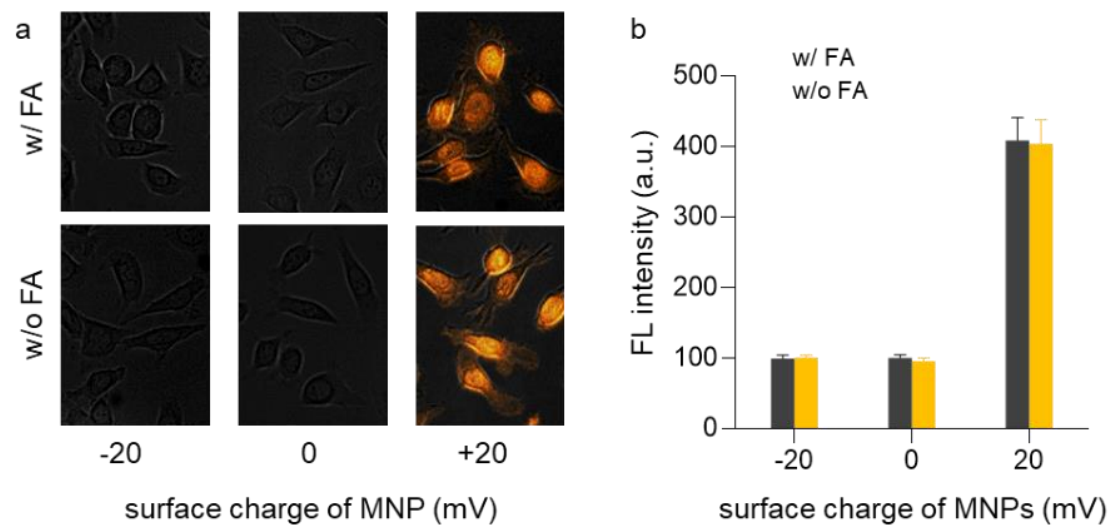

Figure S15. (a) Optical FL images and (b) FL intensity of A594 cells stained by the MNPs with varying surface charge in the presence (top) and absence (bottom) of the folic acid (FA) targeting moiety. 


\section{REFERENCE}

1. Lee, J. H.; Jang, J. T.; Choi, J. S.; Moon, S. H.; Noh, S. H.; Kim, J. W.; Kim, J. G.; Kim, I. S.; Park, K. I.; Cheon, J., Exchange-Coupled Magnetic Nanoparticles for Efficient Heat Induction. Nat. Nanotechnol. 2011, 6 (7), 418-422.

2. Davidson, R. L.; Sittig, M. Water Soluble Resins, 2nd ed.; Reinhold Book Corp.: New York, 1968.

3. Wang, J.; Tsuzuki, T.; Tang, B.; Cizek, P.; Sun, L.; Wang, X., Synthesis of Silica-Coated ZnO Nanocomposite: the Resonance Structure of Polyvinyl Pyrrolidone (PVP) as a Coupling Agent. Colloid Polym. Sci. 2010, 288 (18), 1705-1711.

4. Ashland Inc. PVP Polyvinylpyrrolidone Polymers; Ashland Inc.: Covington, 2014.

5. Boskovic, M.; Goya, G. F.; Vranjes-Djuric, S.; Jovic, N.; Jancar, B.; Antic, B., Influence of Size Distribution and Field Amplitude on Specific Loss Power. J. Appl. Phys. 2015, 117 (10), 103903.

6. Shasha, C.; Krishnan, K. M., Nonequilibrium Dynamics of Magnetic Nanoparticles with Applications in Biomedicine. Adv. Mater. 2020, 1904131.

7. Carrey, J.; Mehdaoui, B.; Respaud, M., Simple Models for Dynamic Hysteresis Loop Calculations of Magnetic Single-Domain Nanoparticles: Application to Magnetic Hyperthermia Optimization. J. Appl. Phys. 2011, 109 (8), 083921.

8. Sanz, B.; Calatayud, M. P.; De Biasi, E.; Lima, E.; Mansilla, M. V.; Zysler, R. D.; Ibarra, M. R.; Goya, G. F., In Silico before In Vivo: How to Predict the Heating Efficiency of Magnetic Nanoparticles within the Intracellular Space. Sci. Rep. 2016, 6 (1), 38733.

9. Rosensweig, R. E., Heating Magnetic Fluid with Alternating Magnetic Field. J. Magn. Magn. Mater. 2002, 252, 370-374.

10. Cobianchi, M.; Guerrini, A.; Avolio, M.; Innocenti, C.; Corti, M.; Arosio, P.; Orsini, F.; Sangregorio, C.; Lascialfari, A., Experimental Determination of the Frequency and Field Dependence of Specific Loss Power in Magnetic Fluid Hyperthermia. J. Magn. Magn. Mater. 2017, 444, 154-160.

11. Pustovalov, V. K., Theoretical Study of Heating of Spherical Nanoparticle in Media by Short Laser Pulses. Chem. Phys. 2005, 308 (1), 103-108.

12. Siegel, R.; Howell, J. R. Thermal Radiation Heat Transfer, 5th ed.; Taylor and Francis: New York, 2010.

13. Carslaw, H. S.; Jaeger, J. C. Conduction of Heat in Solids, 2nd ed.; Clarendon Press: Oxford, 1986.

14. Coene, A.; Leliaert, J., Simultaneous Coercivity and Size Determination of Magnetic Nanoparticles. Sensors 2020, 20 (14), 3882.

15. Landi, G. T., Simple Models for the Heating Curve in Magnetic Hyperthermia Experiments. J. Magn. Magn. Mater. 2013, 326, 14-21.

16. Hu, M.; Hartland, G. V., Heat Dissipation for Au Particles in Aqueous Solution: Relaxation Time versus Size. J. Phys. Chem. B 2002, 106 (28), 7029-7033.

17. Plech, A.; Kotaidis, V.; Grésillon, S.; Dahmen, C.; von Plessen, G., Laser-Induced Heating and Melting of Gold Nanoparticles Studied by Time-Resolved X-Ray Scattering. Phys. Rev. B 2004, 70 (19), 195423.

18. Wu, Z. W.; Kob, W.; Wang, W.-H.; Xu, L., Stretched and Compressed Exponentials in the Relaxation Dynamics of a Metallic Glass-Forming Melt. Nat. Commun. 2018, 9 (1), 5334.

19. Alvarez, F. X.; Jou, D., Boundary Conditions and Evolution of Ballistic Heat Transport. J. Heat Transfer 2009, $132(1)$.

20. Siemens, M. E.; Li, Q.; Yang, R.; Nelson, K. A.; Anderson, E. H.; Murnane, M. M.; Kapteyn, H. C., QuasiBallistic Thermal Transport from Nanoscale Interfaces Observed Using Ultrafast Coherent Soft X-Ray Beams. Nat. Mater. 2010, 9 (1), 26-30.

21. Yang, R.; Chen, G.; Laroche, M.; Taur, Y., Simulation of Nanoscale Multidimensional Transient Heat Conduction Problems Using Ballistic-Diffusive Equations and Phonon Boltzmann Equation. J. Heat Transfer 2005, 127 (3), 298-306.

22. Lin, F.-C.; Zink, J. I., Probing the Local Nanoscale Heating Mechanism of a Magnetic Core in Mesoporous Silica Drug-Delivery Nanoparticles Using Fluorescence Depolarization. J. Am. Chem. Soc. 2020, 142 (11), 5212-5220.

23. Gong, Y.; Fan, M.; Gao, F.; Hong, J.; Liu, S.; Luo, S.; Yu, J.; Huang, J., Preparation and Characterization of Amino-Functionalized Magnetic Nanogels via Photopolymerization for MRI Applications. Colloids Surf. B 2009, 71 (2), 243-247.

24. Dubinsky, S.; Grader, G. S.; Shter, G. E.; Silverstein, M. S., Thermal Degradation of Poly(acrylic acid) Containing Copper Nitrate. Polym. Degrad. Stab. 2004, 86 (1), 171-178. 
25. Xiong, C. H.; Zheng, Y. Q.; Feng, Y. J.; Yao, C. P.; Ma, C. A.; Zheng, X. M.; Jiang, J. X., Preparation of a Novel Chloromethylated Polystyrene-2-amino-1,3,4-thiadiazole Chelating Resin and Its Adsorption Properties and Mechanism for Separation and Recovery of Pt(IV) from Aqueous Solutions. J. Mater. Chem. A 2014, 2 (15), 5379-5386.

26. Haloi, D. J.; Mandal, P.; Singha, N. K., Atom Transfer Radical Polymerization of Glycidyl Methacrylate (GMA) in Emulsion. J. Macromol. Sci. A 2013, 50 (1), 121-127.

27. Lin, Y. S.; Lee, H. H.; Lee, W. F.; Lin, C. H., Synthesis and Qualitative Analysis of BACy and Its Selfpolymer. J. Chin. Chem. Soc. 2013, 60 (2), 223-228.

28. Farrukh, A.; Akram, A.; Ghaffar, A.; Hanif, S.; Hamid, A.; Duran, H.; Yameen, B., Design of PolymerBrush-Grafted Magnetic Nanoparticles for Highly Efficient Water Remediation. ACS Appl. Mater. Inter. 2013, $5(9), 3784-3793$.

29. McNeill, I. C.; Sadeghi, S. M. T., Thermal Stability and Degradation Mechanisms of Poly(acrylic acid) and Its Salts: Part 1-Poly(acrylic acid). Polym. Degrad. Stab. 1990, 29 (2), 233-246.

30. Jaymand, M., Synthesis and Characterization of Novel Type Poly(4-chloromethyl styrene-grft-4vinylpyridine) $/ \mathrm{TiO}_{2}$ Nanocomposite via Nitroxide-mediated Radical Polymerization. Polymer 2011, 52 (21), 4760-4769.

31. Jin, J. M.; Lee, J. M.; Ha, M. H.; Lee, K.; Choe, S., Highly Crosslinked Poly(glycidyl methacrylate-codivinyl benzene) Particles by Precipitation Polymerization. Polymer 2007, 48 (11), 3107-3115.

32. Han, S. C.; He, W. D.; Li, J.; Li, L. Y.; Sun, X. L.; Zhang, B. Y.; Pan, T. T., Reducible Polyethylenimine Hydrogels with Disulfide Crosslinkers Prepared by Michael Addition Chemistry as Drug Delivery Carriers: Synthesis, Properties, and In Vitro Release. J. Polym. Sci. Pol. Chem. 2009, 47 (16), 4074-4082.

33. Iannazzo, D.; Piperno, A.; Ferlazzo, A.; Pistone, A.; Milone, C.; Lanza, M.; Cimino, F.; Speciale, A.; Trombetta, D.; Saija, A.; Galvagno, S., Functionalization of Multi-Walled Carbon Nanotubes with Coumarin Derivatives and Their Biological Evaluation. Org. Biomol. Chm. 2012, 10 (5), 1025-1031. 